\title{
A INFLUÊNCIA DO GESTOR NA SOBREVIVÊNCIA DAS EMPRESAS VAREJISTAS DE PNEUS NA BAHIA
}

Jason Amorim ${ }^{1}$

Lindomar Silva ${ }^{2}$

Miguel Rivera Castro ${ }^{2}$

Rodrigo Ladeira ${ }^{1}$

\footnotetext{
${ }^{1}$ Universidade Federal da Bahia

2 UNIFACS
} 


\section{A INFLUÊNCIA DO GESTOR NA SOBREVIVÊNCIA DAS EMPRESAS VAREJISTAS DE PNEUS NA BAHIA}

\section{Resumo:}

O objetivo deste estudo foi relacionar fatores organizacionais e ambientais para verificar se as características do gestor, tais como escolaridade, gênero, liderança e experiência, se destacaram como influenciadores na sobrevivência das empresas varejistas de pneus na Bahia, entre os anos de 2000 a 2014. A abordagem da estratégia como prática serviu como base teórica. Para medir a relação entre as variáveis de interesse foi utilizado o modelo logístico de análise de regressão. Os resultados demonstraram que o gestor teve influência na sobrevivência das empresas em três variáveis (Gestão Própria, Empresa familiar e Escolaridade), entretanto outros fatores dividiram esta responsabilidade com os gestores: a prática estratégica da relação com o fornecedor; e o ambiente com o PIB e a Frota Média. Outro resultado foi que todas as empresas extintas eram geridas por homens e todas as 21 empresas geridas por mulheres estão entre as sobreviventes no período.

Palavras-chave: Gestor. Varejo. Sobrevivência Empresarial.

\section{Introdução}

Estudar a sobrevivência de empresas tem grande relevância para a economia de uma sociedade, principalmente na atualidade brasileira onde se vive uma crise econômica sem precedentes. Segundo o Instituto Brasileiro de Geografia e Estatística - IBGE (2016), a pesquisa mensal de emprego nas principais regiões metropolitanas do Brasil tem confirmado a queda no rendimento e a subida na taxa de desocupação da população. Como a fonte, tanto do rendimento quanto da ocupação da população, são as empresas, estas estatísticas do IBGE corroboram com a elevação da mortalidade de empresas em todo o país. Segundo dados do IBPT - Instituto Brasileiro de Planejamento e Tributação (2016), somente no ano de 2015 um total de 581.415 micro e pequenas empresas (MPEs) foram fechadas no Brasil. Vale salientar que as MPEs representaram 94\% das empresas ativas no Brasil em 2015 (IBPT, 2016).

Muitos estudos já realizados no Brasil, sobre as causas de fracasso de pequenas empresas, já apontavam os gestores como principais responsáveis por causar a morte de suas organizações. Dentre estes fatores estão: ausência de planejamento prévio ou plano de negócios; falta de capital/lucro; falta de inovação, design ou desempenho dos produtos e serviços; dificuldade em conquistar e manter clientes; nível elevado de concorrência; baixo nível de escolaridade do empreendedor; e competência gerencial diminuta (FERREIRA et al. 2012; SEBRAE-SP, 2014). Esse é um aspecto explorado em algumas abordagens sobre o

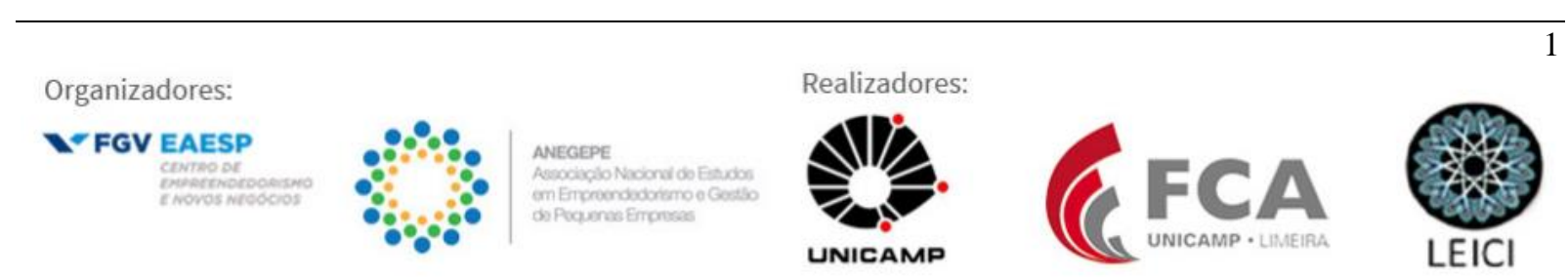


crescimento e a sobrevivência de empresas, as quais destacam a importância do perfil dos dirigentes no conjunto de fatores internos que podem ser utilizados para explicar o desempenho das empresas. (SOUZA et al, 2014). Mas será o administrador o único responsável pelo fracasso ou sucesso das empresas?

Para responder a esta pergunta, o foco deste estudo será o comércio varejista de pneus, predominantemente formado por empresas de pequeno porte, cumpre seu papel relevante à sociedade brasileira e tem seu valor reconhecido também pela Associação Nacional da Indústria de Pneumáticos (ANIP), que é a organização formada pelas indústrias de pneus e câmaras pneumáticas instaladas no Brasil. Segundo a ANIP (2015), no ano de 2013 as empresas brasileiras varejistas de pneus foram responsáveis por comercializar $52 \%$ do volume dos pneus produzidos por suas associadas, além dos 5,88 milhões de pneus importados no mesmo ano também por suas indústrias associadas. Como em 2013 foram 72,8 milhões de unidades produzidas no Brasil, o volume total de produzidos e importados que o varejo comercializou foi 42 milhões de pneus em apenas um ano.

Para comercializar este significativo volume de pneus, este setor do varejo gerava, em 2014, cerca de 40 mil empregos diretos em todo o Brasil, sendo assim maior empregador do que a própria indústria pneumática, pois esta emprega 29 mil empregados (ANIP, 2015). Além da geração de emprego e renda, o setor é grande arrecadador de impostos. Mesmo com tanta importância ao setor industrial e à economia brasileira, a rede de revendas de pneus, formada por empresas varejistas vinculadas às indústrias associadas à ANIP, que já somavam em 2013 mais de 4 mil pontos de vendas em todo o país (ANIP, 2015), tem sofrido muitas oscilações e instabilidade no mercado.

Nos últimos 15 anos muitas mudanças abalaram o varejo de pneus, com novos canais de vendas e empresas entrantes, produtos substitutos e muita rivalidade entre os concorrentes. Em estudo recente feito com empresas varejistas de pneus na cidade de Salvador, foi identificado que o surgimento de novas populações de organizações na comunidade do varejo de pneus em Salvador foi a principal mudança que afetou o ciclo de vida das organizações do setor (SANTOS, 2015). Ainda segundo Santos (2015), outros fatores do ambiente mercadológico também impactaram as empresas do setor, como a abertura do mercado brasileiro para os pneus importados; mudanças no perfil e comportamento do consumidor; a instalação de novas indústrias de pneus no Brasil; e as mudanças governamentais.

Para a análise da influência do gestor na sobrevivência das empresas diante da competitividade crescente, a abordagem teórica da estratégia como prática (SAP) será a principal orientação dos estudos. A estratégia como prática tem o foco de sua investigação nos praticantes da estratégia nas organizações, o que fazem e em como eles atuam e interagem para a realização das práticas estratégicas (WHITTINGTON, 2004; JARZABKOWSKI e WILSON, 2004; VALADÃO e SILVA, 2012; VILLAR e al, 2015; JARZABKOWSKI et al, 2015). Mesmo estando entre os praticantes das estratégias, os gestores se destacam na importância na sobrevivência das empresas, por terem atribuições como diferenciação de habilidades em relação aos demais atores organizacionais e responsabilidade por resultados, sendo classificados classificaram os gestores como praticantes centrais da estratégia, (MACIEL e AUGUSTO, 2015).

Nesse sentido, o objetivo deste estudo é relacionar fatores organizacionais e ambientais para verificar se as características do gestor, tais como escolaridade, gênero, habilidades e
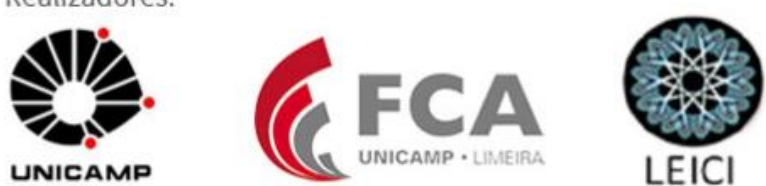
experiência, se destacaram como fator influenciador da sobrevivência das empresas varejistas de pneus na Bahia, tendo como objetivos específicos: a) analisar se as empresas geridas pelos proprietários ou um dos sócios tiveram mais chances de sobrevivência; b) avaliar se a escolaridade do gestor influenciou na sobrevivência de suas respectivas empresas; c) se o gênero do gestor teve influência na sobrevivência empresarial; d) se habilidades e experiência prévia do gestor garantem o sucesso das empresas.

Do ponto de vista metodológico, este estudo é quantitativo. A amostra analisada é composta por empresas varejistas de pneus, instaladas em cidades de todo o estado da Bahia. O período pesquisado será dos anos 2000 a 2014, onde atuaram no varejo baiano de pneus 1.124 empresas, segundo dados cadastrais da Junta Comercial da Bahia (JUCEB). A análise dos dados será feita através do modelo de Regressão Logística Binária com variáveis explicativas que representam os fatores ambientais e organizacionais.

Em seguida são apresentados os resultados do modelo de análise. Logo após, disponibilizam-se as discussões dos dados, seguindo às considerações finais contendo as conclusões e contribuições do estudo, os limites da pesquisa e previsões de estudos futuros.

\section{Referencial Teórico}

O interesse neste estudo está nas "estruturas em uso", no modo como os indivíduos se utilizam das estruturas para realizarem suas atividades e assim reproduzirem ou modificarem essas estruturas (WHITTINGTON, 2004), inclusive reconhecendo o fato de que mais importante do que a configuração estrutural em si é o modo como pessoas as administram no seu cotidiano organizacional. Este interesse pelo cotidiano organizacional onde se administram as "estruturas em uso" e se produz a estratégia, levou à opção teórica da visão da escolha estratégica na perspectiva da estratégia como prática (do original em inglês Strategy as Practice - SAP), que se caracteriza, principalmente, pela proposição de que a estratégia não é mais algo que as organizações possuem, mas, sim, aquilo que as pessoas fazem (JARZABKOWSKI; BALOGUN; SEIDL, 2007; SILVA ANDRADE et al., 2016), de modo que o pesquisador está interessado no 'trabalho estratégico' (strategizing), procurando identificar os três elementos da estratégia importantes para a atual teoria da prática: o que eles fazem, quem faz e como fazem na prática e, a partir daí, quais as implicações de suas ações na formação da estratégia organizacional (JARZABKOWSKI et al, 2015; WHITTINGTON, 2004; JARZABKOWSKI; BALOGUN; SEIDL, 2007; VAARA; WHITTINGTON, 2012; MACIEL; AUGUSTO, 2013; VILLAR et al, 2015).

\subsection{Praticantes}

Os praticantes são considerados os pontos importantes de conexão entre a práxis intraorganizacional e as práticas organizacionais e supra-organizacionais, as quais estes utilizam para construir a práxis. Um dos pontos sobre praticantes da estratégia que esta pesquisa buscará compreender é como estes profissionais são "produzidos" por meio de sua formação acadêmica e das carreiras que desenvolveram tanto antes como durante a gestão e/ou atuação em suas respectivas empresas. Outro ponto importante nesta pesquisa é também por estudar não só os dirigentes, mas todos os praticantes envolvidos na prática das estratégias
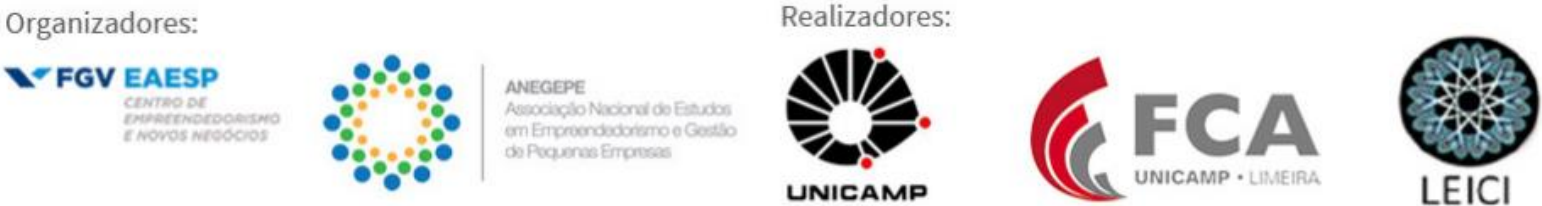
da empresa. O praticante é qualquer indivíduo socialmente inserido, o qual, independentemente de sua posição hierárquica, contribui por meio de suas ações e interações para a estratégia da organização (WHITTINGTON, 2004; JARZABKOWSKI e WILSON, 2004; VILLAR et al, 2015; MACIEL e AUGUSTO, 2015).

O gestor ou o administrador não será isolado, mas incluído como parte da organização e não a própria organização. No âmbito dos fatores organizacionais o gestor será estudado dentre os praticantes da estratégia, bem como os que fazem e como fazem. Nessa mesma direção para a prática, a perspectiva da estratégia como prática assume que os atores não podem ser deslocados do contexto social, já que as atividades e estruturas sociais estão relacionadas (TURETA E LIMA, 2011).

Maciel e Augusto (2015) aprofundaram seus estudos sobre os praticantes da estratégia, classificando-os em uma formação tripartite: praticantes centrais, semiperiféricos e periféricos. Essa hierarquia ocorre em função do grau de atribuição de determinados significados a papéis, ou rótulos ocupacionais (diretor, coordenador, operário). Estes autores classificaram os gestores como praticantes centrais da estratégia, por terem atribuições como diferenciação de habilidades em relação aos demais atores organizacionais e responsabilidade por resultados.

Entretanto, os gestores não serão os únicos praticantes estudados, mas incluídos entre os praticantes das estratégias das empresas. Variáveis derivadas do conceito de Capital Humano também serão utilizadas nos fatores organizacionais desta pesquisa, e espera-se um efeito positivo destas variáveis na sobrevivência de empresas, pois a capacidade adquirida pelo conhecimento do empreendedor deve influenciar seu potencial para analisar o setor, formular ações que possibilitem o melhor retorno possível, dominar e equacionar os investimentos necessários. Dessa forma, quanto maior o nível de escolaridade, de treinamento e de experiência acumulada pelo empreendedor, maior deve ser a probabilidade de sobrevivência de seu empreendimento (MIZUMOTO ET AL, 2010).

Como as empresas varejistas de pneus são predominantemente formadas por micro e pequenas empresas, isto nos leva à discussão sobre outro tema, o da empresa familiar. É largamente conhecido que as empresas familiares são motores importantes da atividade e crescimento econômico em todo o mundo. Contudo, sabe-se também que a mortalidade da empresa familiar é bastante alta (NELSON; PIMENTEL, 2015).

Segundo Domingues et al (2016), em empresas familiares pode ocorrer a sobreposição entre a administração e a propriedade da empresa, como acontece nas empresas varejistas de pneus com gestão própria, porque não existe nenhuma distinção entre 'principal' e 'agente', entre proprietário e gestor (NELSON; PIMENTEL, 2015; DOMINGUES et al, 2016). Todavia também podem ter empresas com a administração e propriedade dissociada, onde os administradores são profissionais de fora do grupo familiar ou algum familiar contratado para este fim e com isto, os donos do capital passam a não serem os responsáveis diretos pela sua gestão (DOMINGUES et al, 2016). Eles têm legitimidade, mas teoricamente, acesso limitado à aplicação e manipulação de capital. Em tal situação, enquanto um é visto como o ator 'principal' (pessoa demandante da representação); o outro se torna o 'agente', pessoa selecionada para representar o demandante e desempenhar uma ação (NELSON; PIMENTEL, 2015).
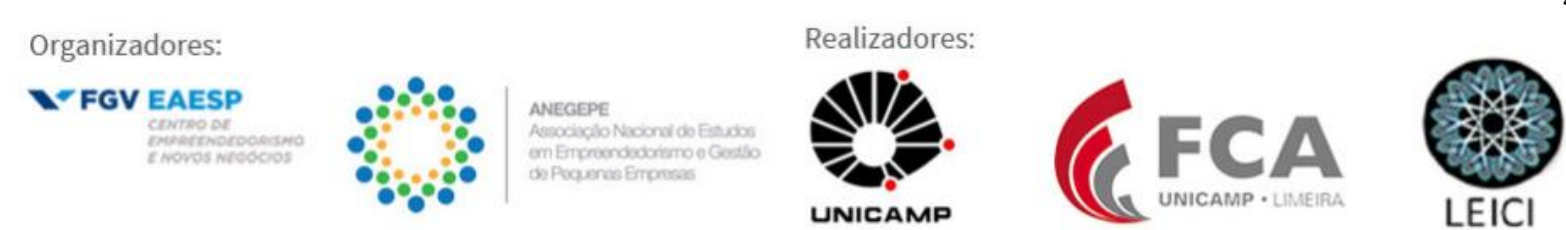


\subsection{Práxis}

Ainda em relação à abordagem da Estratégia Como Prática, conforme pesquisadores vinculados a essa corrente alertam (WHITTINGTON, 2002; JARZABKOWSKI e WILSON, 2004; WHITTINGTON, 2004; JARZABKOWSKI et al, 2015), é necessário não só estudar as atividades e práticas dos indivíduos na organização, mas quais modelos e ferramentas estão sendo utilizados e como estão sendo utilizados, ou seja, urge estudar as atividades cotidianas onde as práticas tomam corpo (WHITTINGTON, 2004;JARZABKOWSKI; BALOGUN; SEIDL, 2007; CANHADA e RESE, 2009; VAARA; WHITTINGTON, 2012; VILLAR et al, 2015).

Buscando uma definição para o conceito de práxis no contexto da pesquisa em estratégia como prática, Whittington (2002) a apresenta como o trabalho real dos praticantes da estratégia, conforme eles se utilizam, modificam e replicam as práticas da estratégia. Assim, conforme Jarzabkowski, Balogun e Seidl (2007), a práxis estratégica se refere a fluxos de atividade situados em contexto social amplo, possuindo impactos significativos no direcionamento e sobrevivência da organização ou de todo o setor industrial.

A práxis refere-se às atividades que estão sendo realizadas, ou seja, o que as pessoas fazem e os efeitos que produzem no cotidiano organizacional e que possuem alguma relação com o processo de formulação e implementação das estratégias. Embora essas atividades se manifestem de maneira esparsa na organização, elas podem ser observadas em reuniões, intervenções de consultorias, instruções de equipes ou grupos, apresentações e simples conversas. Contemplam tanto aspectos rotineiros como não rotineiros, formais e informais, atividades organizacionais centrais e periféricas (WHITTINGTON, 2006).

A práxis da estratégia pode também ser explicada por meio dos níveis micro (episódios específicos, reuniões ou workshops), meso (mudanças de planejamento e padrões de ação estratégicos) ou macro (padrões de ação de um setor industrial) (TURETA E LIMA, 2011). Eis então mais uma característica da SAP que será muito importante neste estudo sobre a morte e a vida das empresas varejistas de pneus, porque serão analisadas, de forma integrada, variáveis vinculadas a fatores organizacionais e ambientais. Serão analisadas as práxis das organizações nos níveis micro, meso e macro.

Como é no cotidiano organizacional onde se observam a práxis, uma parcela importante do trabalho dos estrategistas, pontualmente ao fazer estratégia (strategizing), acontece em uma sequência de episódios de práxis, tais como conversas formais, conversas de corredor, telefonemas, projetos, entre outros, nos quais existe interação entre os atores. (VILLAR et al, 2015). A práxis abrange, portanto, episódios formais e informais, rotineiros e não rotineiros, que contemplam desde a diretoria até o "chão de fábrica" da organização. Todas as atividades envolvidas na formulação e implementação da estratégia estão compreendidas nos diversos episódios de práxis, esta constitui o elo entre o que os indivíduos fazem e o que acontece nas organizações e é onde o trabalho de fazer a estratégia toma corpo (JARZABKOWSKI; BALOGUN; SEIDL, 2007; VAARA e WHITTINGTON, 2012; VILLAR et al 2015)

\subsection{Práticas}

Para muitos autores, as práticas dizem respeito a rotinas compartilhadas de relacionamento, que podem incluir tradições, normas, métodos, procedimentos de pensar, agir

\section{Organizadores:}

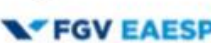

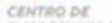
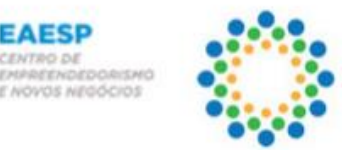

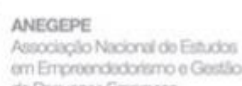

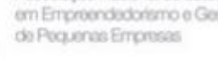
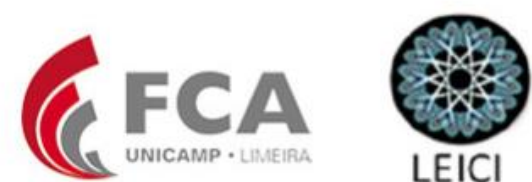
e utilizar ferramentas para fazer a estratégia (WHITTINGTON, 2007; JARZABKOWSKI; BALOGUN; SEIDL, 2007, VAARA; WHITTINGTON, 2012; VILLAR et al, 2015). Um caminho possível para entender o estrategizar, então, é atentar com mais cuidado para a dimensão das práticas localizadas, sem desvincular-se do contexto (TURETA E LIMA, 2011).

O enfoque, portanto, passa a ser entender a estratégia como um fluxo das atividades organizacionais, em que dicotomias como pensar/agir e formulação/ implementação são suprimidas no permanente movimento de construção das práticas estratégicas (JARZABKOWSKI; BALOGUN; SEIDL, 2007). A prática da estratégia pode ser entendida como "a interação e interpretação por meio das quais a atividade estratégica emerge a todo o tempo" (JARZABKOWSKI e WILSON, 2004), referindo-se a todo o processo de formulação, implementação e comunicação das estratégias (WHITTINGTON, 2004; TURETA e LIMA, 2011).

São constituídas tanto de aspectos locais (organizacionais), próprios de uma dada organização e incorporados em suas rotinas, quanto de elementos explícitos (supraorganizacionais) derivados de um campo social mais amplo no qual a organização se encontra inserida, como práticas setoriais, técnicas de estratégia, normas de comportamento estratégico, sendo portanto o foco das ações do estrategista nas micro e macroatividades dos indivíduos e das organizações (WHITTINGTON, 2007; VALADÃO e SILVA, 2012). As práticas são constituídas por atividades organizadas, nas quais os participantes operam em uma arena onde determinadas ações e fins podem ser prescritos ou aceitáveis em certas ocasiões, representando um envolvimento temporário de um conjunto de ações e dizeres (TURETA e LIMA, 2011).

Estudar a estratégia com base nesse prisma analítico requer a busca de explicações sobre como os atores a concebem em suas interações sociais com outros atores, recorrendo a práticas específicas dentro de um determinado contexto (JARZABKOWSKI et al, 2015). É ainda conhecer onde e quando as interações ocorrem e como os atores (re)constituem um sistema de práticas estratégicas compartilhadas (JARZABKOWSKI e WILSON, 2004; TURETA e LIMA, 2011).

Esses atores entendem as estratégias como atividades que estão conectadas com práticas específicas do universo organizacional, tais como o planejamento estratégico, relatórios anuais, reuniões, conferências, etc.(SILVA ANDRADE et al, 2016)

Os estudos em estratégia como prática têm revelado as práticas estratégicas como complexas, flexíveis, e polivalentes (VAARA; WHITTINGTON, 2012). As práticas vão além da simples análise da estratégia racional, pois envolvem também questões sociais e materiais. As práticas habilitam os atores a interagirem socialmente, realizando assim suas atividades de forma coletiva (WHITTINGTON, 2006; JARZABKOWSKI; BALOGUN; SEIDL, 2007; VILLAR et al, 2015).

Para entender melhor a sabedoria da prática, são necessários estudos detalhados em um nível micro sobre as práticas iterativas que os estrategistas utilizam para se engajar em atividades práticas, e também sobre suas intenções ou projeções para utilizar essas práticas (JOHNSON et al., 2007; JARZABKOWSKI e WILSON, 2004; VALADÃO e SILVA, 2012).

Dentre as práticas comuns a todos os varejistas de pneus, está a relação com a indústria fornecedora de pneus. Sendo assim, as relações Business-To-Business entre o varejo
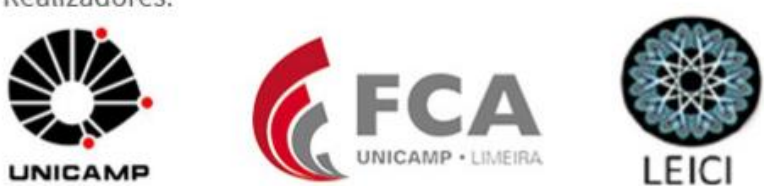
e a indústria pneumática será também analisada como fator de influência na sobrevivência das empresas varejistas de pneus na Bahia.

A perspectiva da Estratégia como Prática (Strategy as Practice - SAP) é um campo de estudos relativamente recente, pois em 2016 completam 20 anos de pesquisa, e considera que o fenômeno da estratégia organizacional não é mais algo que as organizações possuem, mas sim aquilo que as pessoas fazem no cotidiano organizacional (JARZABKOWSKI; BALOGUN; SEIDL, 2007; SILVA ANDRADE et al., 2016). Além de ser considerado um campo de estudos relativamente recente, a SAP continua em processo de aprimoramento e pesquisas, concluindo-se que a virada da prática nos estudos sobre estratégia não está completa (MACIEL e AUGUSTO, 2013).

Uma das mais recentes proposições apresentadas por Jarzabkowski et al (2015) alerta sobre o risco da limitação conceitual em se estudar a estratégia como prática com o foco em apenas um dos elementos do strategizing. Segundo estes autores, é de suma importância que, além de estudar os três elementos (praticantes, práxis e práticas), que eles sejam integrados. Propõem assim, o modelo integrado da prática estratégica. A elevação das práticas acima da práxis e dos praticantes é, portanto, susceptível de conduzir a conclusões erradas. Sem uma valorização da dependência mútua entre "o que, quem e como", corre-se o risco de atribuição incorreta diferenciais de desempenho e, consequentemente, oferecer conselhos equivocados para os profissionais de estratégia (JARZABKOWSKI et al, 2015).

Sendo assim, para embasar os estudos dos fatores organizacionais deste estudo, será utilizada a abordagem teórica da estratégia como prática (SAP), através dos três elementos apresentados que compõem o conceito do strategizing: praticantes, práxis e práticas. E para não correr o risco alertado por Jarzabkowski et al (2015), estes elementos serão estudados de forma integrada.

\section{Metodologia}

Para medir quantitativamente a relação entre as variáveis de interesse e a influência do gestor na sobrevivência das empresas que compõem a amostra, foi utilizada a abordagem baseada na modelagem da probabilidade de estar morta utilizando modelos logísticos (FÁVERO, 2015). A variável explicada ou dependente é dicotômica e indica se a empresa permanece ativa (0) ou encerrada (1). Foram consideradas como ativas as empresas que estavam funcionando em 31 de dezembro de 2014.

\subsection{Universo e Amostra}

Foi utilizada inicialmente a base de dados cadastrais da Junta Comercial do Estado da Bahia (JUCEB), sendo feitas consultas complementares no Cadastro Nacional de Pessoa Jurídica (CNPJ) da Secretaria da Receita Federal (SRF). O ponto de partida para a seleção das empresas que formam a população de empresas varejistas de pneus foi a Classificação Nacional de Atividades Econômicas (CNAE). A população de organizações, analisada neste estudo, é formada por empresas registradas com atividade principal ou secundária no CNAE 4530705 (Comércio a varejo de pneumáticos e câmaras de ar).

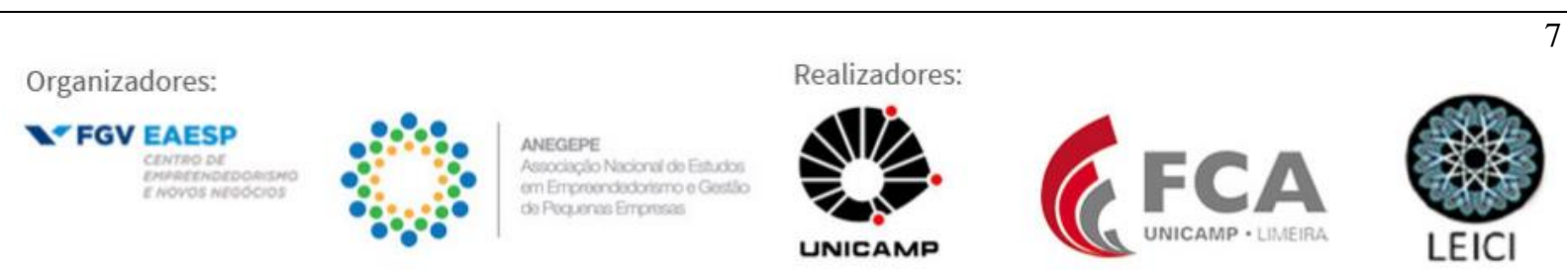


Com relação às informações específicas das empresas que compõem a amostra principal, foram formatados dois Questionários no Google Forms, com fácil preenchimento online, e distribuído às empresas do setor por email ou através de entrevistas pessoais. Segundo a JUCEB, no período de 2000 a 2014, atuaram na Bahia 1.124 empresas com o CNAE 4530705. Deste total, foram obtidos 236 Formulários de respostas, referentes a 236 empresas varejistas de pneus instaladas em 34 cidades de todas as regiões do estado da Bahia, sendo 57 empresas que encerraram suas atividades no período e 179 que estavam ativas em 31 de dezembro de 2014.

Como complementação das informações obtidas via questionários, foram entrevistados seis gestores de empresas ativas. A pesquisa foi feita nos meses setembro, outubro e novembro de 2016. A amostra objeto desta pesquisa, portanto, é formada por 236 empresas varejistas de pneus da Bahia.

\subsection{Variáveis para Análise}

Dos fatores de análise surgiram as variáveis que ajudaram a responder a pergunta deste estudo, se a vida das empresas é determinada pelas restrições ambientais ou depende ativamente das suas escolhas, práticas e praticantes das estratégias Foram utilizadas tanto variáveis métricas, claramente quantitativas, como também as variáveis não métricas, também conhecidas como variáveis qualitativas, as quais foram transformadas em variáveis dummies, também conhecidas como variáveis binárias.

Portanto, a partir das dimensões apresentadas, foram definidas as variáveis organizacionais e ambientas. Segue então a relação das variáveis preditas e preditoras descritas na Figura 1 abaixo.

Figura 1 - Relação das variáveis

\begin{tabular}{|c|c|c|c|c|}
\hline Variável & Descrição & Dimensão & Fonte & Questão \\
\hline GESTAO & Gestão Própria & Organizacional & Questionário & 3 \\
\hline EMPFAM & Empresa familiar & Organizacional & Questionário & 4 \\
\hline NEMPREG & Número de empregados & Organizacional & Questionário & 5 \\
\hline ESPEC & Especialista ou generalista & Organizacional & Questionário & 8 \\
\hline IDADEGEST & Idade Gestor & Organizacional & Questionário & 10 \\
\hline ESCGESTOR & Escolaridade do Gestor & Organizacional & Questionário & 11 \\
\hline EXPRAMO & Experiência no Ramo & Organizacional & Questionário & 15 \\
\hline EXPLIDER & Experiência de Liderança & Organizacional & Questionário & 16 \\
\hline MONOMARCA & Relação com fornecedores & Organizacional & Questionário & 22 \\
\hline PIBMEDIO & Média do PIB & Ambiental socioeconômica & SEI - BA & \\
\hline FROTAMEDIA & Frota de Veículos & Ambiental mercadológica & DETRAN-BA & \\
\hline STATUS & Empresas ativas & Y & JUCEB / SRF & \\
\hline STATUS & Empresas encerradas & Y=1 & JUCEB /SRF & \\
\hline VIDADIAS & Tempo de vida em dias & Y & JUCEB / SRF & \\
\hline
\end{tabular}

Fonte: Elaborado pelos autores

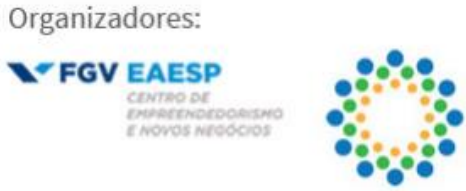




\section{Apresentação e Análise dos Resultados.}

Foram obtidos 236 Formulários de respostas, referentes a 236 empresas varejistas de pneus instaladas em 34 cidades de todas as regiões do estado da Bahia, sendo 101 empresas na Capital e 135 em cidades do interior do estado. Em relação à situação das empresas, 57 estavam extintas (24\%) e 179 em atividade (76\%) até o dia 31 de dezembro de 2014.

Antes de apresentarmos os resultados obtidos através do modelo de análise de regressão logística, é importante destacar uma informação da análise descritiva da amostra relacionada ao perfil do gestor. Com relação ao gênero dos gestores, participaram da pesquisa 215 homens $(91 \%)$ e 21 mulheres (9\%). Todas as empresas extintas eram geridas por homens e todas as 21 empresas geridas por mulheres estão entre as sobreviventes no período. Este sucesso das mulheres gestoras, pois embora tenham sido minoria, poderá suscitar novos estudos principalmente por ser o universo automotivo predominantemente masculino.

Para análise dos dados no modelo de regressão, foi utilizado o software R como apoio para obtenção dos resultados, os quais estão apresentados nas Tabelas 1 abaixo, onde constarão todas as variáveis explicativas e suas relações com os eventos de interesse.

Segue então a Tabela 1 com os resultados das variáveis no modelo de análise de regressão logística.

Tabela 1 - Relação das variáveis organizacionais e ambientais com a mortalidade pelo modelo logístico

\begin{tabular}{cccccc}
\hline Variáveis & Estimador & Erro padrão & Z valor & P valor & Sig \\
\hline Interceptor & $-2.732 \mathrm{e}+00$ & $7.102 \mathrm{e}-01$ & -3.848 & 0.000119 & $* * *$ \\
GESTAO & $-2.006 \mathrm{e}+00$ & $7.353 \mathrm{e}-01$ & -2.728 & 0.006372 & $* *$ \\
EMPFAM & $2.604 \mathrm{e}+00$ & $7.820 \mathrm{e}-01$ & 3.329 & 0.000871 & $* * *$ \\
NEMPREG & $8.684 \mathrm{e}-01$ & $4.120 \mathrm{e}-01$ & 2.108 & 0.035029 & $*$ \\
ESPEC & $-4.524 \mathrm{e}-01$ & $4.394 \mathrm{e}-01$ & -1.029 & 0.303256 & \\
IDADEGEST & $5.556 \mathrm{e}-01$ & $3.808 \mathrm{e}-01$ & 1.459 & 0.144531 & \\
ESCGESTOR & $-8.425 \mathrm{e}-01$ & $4.126 \mathrm{e}-01$ & -2.042 & 0.041141 & $*$ \\
EXPRAMO & $8.166 \mathrm{e}-01$ & $5.096 \mathrm{e}-01$ & 1.603 & 0.109014 & \\
EXPLIDER & $2.051 \mathrm{e}-01$ & $5.233 \mathrm{e}-01$ & 0.392 & 0.695158 & \\
MONOMARCA & $-1.432 \mathrm{e}+00$ & $4.334 \mathrm{e}-01$ & -3.304 & 0.000952 & $* * *$ \\
PIBMEDIO & $2.897 \mathrm{e}-04$ & $1.118 \mathrm{e}-04$ & 2.591 & 0.009575 & $* *$ \\
FROTAMEDIA & $-8.904 \mathrm{e}-06$ & $4.423 \mathrm{e}-06$ & -2.013 & 0.044096 & $*$ \\
\hline
\end{tabular}

Fonte: Elaborado pelos Autores

Para o entendimento dos resultados é importante ressaltar que o modelo Logístico tem uma variável dependente com duas respostas dicotômicas, sendo neste estudo o evento de interesse a "morte" da empresa e o referencial a situação ativa da empresa. Ficando, portanto, definido como $1=$ empresas encerradas no período de 2000 a 2014; e $0=$ empresas ativas.

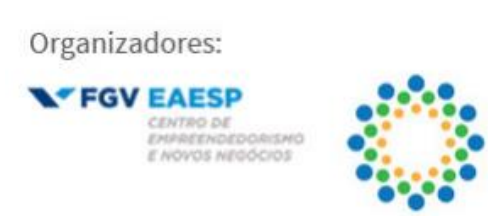


Das onze variáveis preditoras, sete tiveram significância na mortalidade das empresas, sendo três relacionadas ao gestor, uma ao número de empregados, uma relacionada à prática do relacionamento com a indústria e duas relacionadas à influência do ambiente. Seguem-se então às análises agrupadas.

\subsection{A influência do Gestor}

Assim como os estudos realizados por Ferreira et al. (2012), esta pesquisa revela que não existe um fator específico que possa ser responsabilizado isoladamente pelo encerramento das atividades de uma empresa. Dentre os fatores atuantes na sobrevivência empresarial, a primeira variável em destaque foi a variável GESTÃO (Gestão Própria) com efeito negativo em relação à mortalidade. O sinal negativo no resultado do modelo logístico representou menor influência sobre a "morte" da empresa, ou seja, as organizações que eram geridas pelo proprietário ou um dos sócios tiveram menor incidência de extinção. Portanto, o antigo ditado popular "O olho do dono é que engorda o gado" se aplica ao varejo de pneus na Bahia, pois as empresas geridas pelo proprietário ou um dos sócios tiveram menos chances de morte.

Na variável EMPFAM, o sinal positivo no resultado do modelo logístico demonstrou que o fato de a empresa ser gerida por um familiar não era fator de proteção da empresa. Fazse necessário distinguir esta variável da anterior, a GESTÃO. Isto porque todas as empresas que tinham o proprietário ou um dos sócios também como gestores foram consideradas como empresa familiar, mas nem todas as empresas familiares tinham um dos sócios como gestor. Como a variável anterior não influenciou a mortalidade das empresas e esta variável EMPFAM (Empresa Familiar) teve efeito positivo, ou seja, onde existia relação familiar entre os sócios e/ou gestores da empresa, teve maior incidência de extinção na amostra em estudo, o resultado traz um alerta em relação à terceirização do comando da empresa a um familiar.

Maciel e Augusto (2015) classificaram os gestores como praticantes centrais da estratégia, por terem atribuições como diferenciação de habilidades em relação aos demais atores organizacionais e responsabilidade por resultados. Portanto, a preocupação que surgiu nos resultados da regressão logística nesta pesquisa foi o fato de que os gestores que têm relação familiar com os proprietários das empresas, mas não são sócios, têm uma tendência a falir suas respectivas empresas.

O que demonstra, ao relacionarmos os resultados da pesquisa com a teoria da SAP, é que os gestores "familiares" das empresas pesquisadas não têm as habilidades, formação e capacidades necessárias para contribuírem expressivamente no desempenho organizacional e nem influenciam positivamente os outros praticantes a executarem as práxis e as práticas estratégicas com sucesso.

Como o foco desta pesquisa não é a eficácia da empresa familiar, mas a sobrevivência das organizações varejistas de pneus na Bahia, conclui-se que as empresas que tinham a gestão e propriedade dissociada, sendo um familiar como a pessoa selecionada para representar o demandante e desempenhar a ação de gerir, tiveram mais chances de extinção. Com este resultado, urge também outros estudos que possam ter um aprofundamento sobre a necessidade de melhor escolha de um gestor, mesmo este tendo alguma relação familiar com os donos da empresa. Pois a importância do praticante central (o gestor) ter habilidades, formação e capacidades necessárias para o bom desempenho organizacional se sobrepõem a quaisquer rótulos de confiança e afeto de um familiar em relação à sobrevivência empresarial.
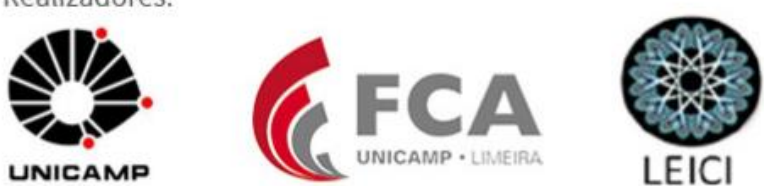
Em relação à escolaridade do gestor, a significância e o sinal negativo da variável ESCGESTOR demonstra que a formação superior dos gestores influenciou menos a morte de suas respectivas empresas. Quanto maior a escolaridade do gestor, menor o risco de morte. Portanto, diferente de Mizumoto et al (2010) e semelhante aos estudos de Ferreira et al (2012), os resultados encontrados nesta pesquisa com os varejistas de pneus da Bahia evidenciam que a escolaridade com formação superior dos gestores teve influência negativa em relação à mortalidade. Ou seja, quanto mais escolaridade menos chance de morte e mais chances de vida. Quando associamos este resultado ao fato que as variáveis relacionadas às experiências anteriores do gestor, tanto no ramo como com liderança (EXPRAMO e EXPLIDER), não tiveram significância, podemos inferir que, diante de um mercado cada vez mais competitivo e instável, mais importante do que a experiência são os novos conhecimentos adquiridos pelos gestores com mais escolaridade.

\title{
4.2. A influência das relações entre indústria e varejo.
}

Outro fator organizacional relevante, a prática estratégica do relacionamento com fornecedores, foi representada na variável MONOMARCA. Inicialmente é importante lembrar a diferença de uma empresa varejista de pneus ser monomarca ou multimarcas. Monomarca significa que a empresa varejista comercializa apenas uma marca de pneus, gozando assim de maior relacionamento com o fornecedor/fabricante. Em troca pelas vendas exclusivas de uma determinada marca de pneus, a empresa varejista conta com as vantagens da parceria com uma organização consagrada mundialmente no mercado pneumático, tanto no que se relaciona à credibilidade do produto junto ao consumidor, quanto no conjunto de práticas e práxis fornecidas e controladas pelo fornecedor. Já as empresas multimarcas têm maior liberdade de gestão e comercialização de seus produtos e, ainda, maior diversidade de marcas ofertadas aos clientes, tendo, porém menor apoio e relação com fornecedores.

Nesta variável MONOMARCA, o sinal negativo no resultado do modelo logístico demonstra que as empresas multimarcas tiveram menor incidência de extinção e comprovam que ser monomarca não traz segurança em relação à morte. Isto contradiz um pensamento que ainda predomina no mercado, segundo um dos gestores entrevistados:

\begin{abstract}
"Ser monomarca é mais seguro para o varejista, porque você ser uma revenda de uma empresa multinacional passa uma imagem de respeito no mercado, além das vantagens de maior relacionamento com seu principal fornecedor. Porém, para se tornar um revendedor autorizado de uma fabricante multinacional é necessário passar por um controle de qualidade onde são analisados recursos disponíveis, localização, PDV, estrutura física e, ainda, seguir padrões utilizados em empresas no mundo inteiro." (ENTREVISTADO 1)
\end{abstract}

Um dos questionamentos neste estudo é que o campo organizacional do varejo de pneus na Bahia já não se apresenta tão estável. Outro fator de instabilidade de mercado que é a entrada no varejo de pneus de outras populações de organizações comercializando pneus diretamente ao consumidor. Segundo Santos (2015), estas outras populações de organizações, como as redes de supermercados e varejistas virtuais, são abastecidas pelos mesmos fabricantes de pneus. Com isto, enquanto as empresas varejistas monomarcas comercializam exclusivamente pneus de um fornecedor/fabricante, este fornece os mesmos produtos para

Organizadores:
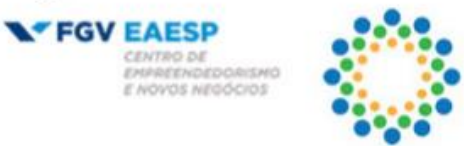

ANEGEPE

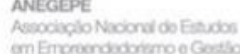

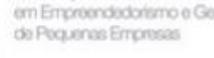

Realizadores:
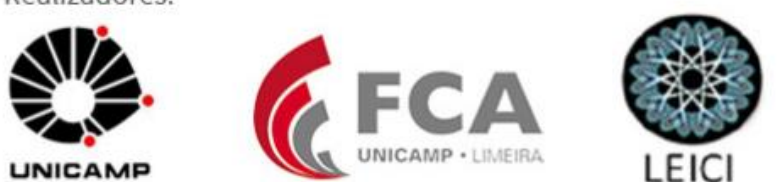
outras populações de organizações e outros concorrentes para comercializarem pneus no mesmo ambiente. Talvez por estas razões é que um dos gestores incluiu, durante a entrevista, entre as principais mudanças no mercado de pneus, o crescimento das empresas multimarcas:

\footnotetext{
"Abertura de mercado brasileiro para os pneus importados, venda de pneus pelo canal e-commerce, a instalação das fábricas de pneus Continental e Dunlop no Brasil e o crescimento dos centros automotivos multimarcas." (ENTREVISTADO 2)
}

Até o início desta pesquisa não houve trabalhos anteriores específicos para analisar as vantagens de ser monomarca ou multimarcas e qual o reflexo desta escolha estratégica na sobrevivência do varejista de pneus. As decisões tomadas sobre o relacionamento com fornecedores, de ter uma ou diversas marcas de pneus a serem vendidos, eram tomadas pela tradição ou por uma prática predominante no mercado. Esta condição foi assim exposta por um dos gestores entrevistados:

\begin{abstract}
"Sempre se acreditou que ser monomarca seria mais vantagem estar sob a proteção do relacionamento com um único fornecedor, do que comprar pneus de outro canal de vendas, os distribuidores. Isto levaria a obter menor lucro e menor relacionamento com os fabricantes, mesmo podendo oferecer ao consumidor uma maior diversidade de produtos e, com isto, ter maior fluxo de vendas." (ENTREVISTADO 3)
\end{abstract}

O relacionamento com fornecedores se enquadra no conceito das práticas estratégicas da SAP, onde muitos autores evocam que as práticas dizem respeito a rotinas compartilhadas de relacionamento, que podem incluir tradições, normas, métodos, procedimentos de pensar, agir e utilizar ferramentas para fazer a estratégia (WHITTINGTON, 2007; JARZABKOWSKI; BALOGUN; SEIDL, 2007, VAARA; WHITTINGTON, 2012; VILLAR et al, 2015). Um caminho possível para entender o estrategizar requer a busca de explicações sobre como os atores concebem a estratégia em suas interações sociais com outros atores, neste caso com os fornecedores de pneus, e atentar com mais cuidado para a dimensão das práticas específicas, sem desvincular-se do contexto (TURETA E LIMA, 2011; JARZABKOWSKI et al, 2015).

Diante desta realidade das práticas estratégicas das relações entre varejistas e fabricantes de pneus, além do ineditismo desta pesquisa, segundo os resultados encontrados com a amostra total, as empresas multimarcas, ou seja, as que optaram pela prática estratégica de se relacionar com diversos fornecedores, tiveram menor incidência de extinção.

\title{
4.3 A influência do ambiente
}

A variável do ambiente socioeconômico, PIBMEDIO, teve significância, porém demonstrou com o sinal positivo que o fato de um município, onde está instalada uma empresa, ter um PIB Médio elevado não protege a empresa da extinção, pois houve maior incidência de morte em empresas instaladas nos municípios com maior PIB médio,

Como estamos associando fatores ambientais com organizacionais, talvez o que possa explicar esta neutralidade do ambiente é o fato de outros fatores sobrepujarem a força do ambiente. Por exemplo, na prática estratégica do relacionamento com fornecedores, 71,9\%
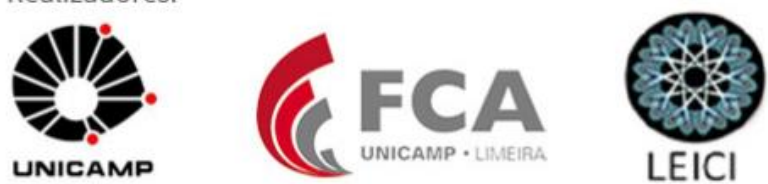
das empresas não sobreviventes eram monomarca e estas tiveram maior incidência de morte e menor tempo de vida. Outros fatores organizacionais como gestão própria e número de empregados também tiveram influência na sobrevivência e, como as empresas instaladas em municípios menores geralmente são geridas pelos proprietários ou sócios e têm menor número de empregados, estas empresas tiveram menor incidência de morte.

Sendo assim, com um olhar meramente quantitativo dos resultados da análise de regressão desta pesquisa, chegaríamos à conclusão que a elevação do PIB Médio causa mais morte às empresas. Neste caso, suspeitar-se-ia de uma incoerência observar nos municípios com maior PIB Médio, também maior mortalidade das empresas varejitas de pneus. Contudo, quando associamos com os fatores organizacionais e outras consequências da dinâmica e desempenho econômico dos municípios, como a evolução da competitividade, concluiremos que o ambiente também foi seletivo.

A significância da variável FROTAMEDIA no modelo de regressão logística demonstra que o ambiente mercadológico também influenciou a vida das empresas, pois o sinal negativo no modelo logístico explica que quanto maior a frota média do município, menor a incidência de morte.

\section{Conclusões}

Com o objetivo de relacionar fatores organizacionais e ambientais para verificar se as características do gestor, tais como escolaridade, gênero, habilidades e experiência, se destacaram como fator influenciador da sobrevivência das empresas varejistas de pneus na Bahia, a metodologia utilizada foi adequada para responder à pergunta da pesquisa: será o administrador o único responsável pelo fracasso ou sucesso das empresas? Os resultados do modelo de regressão logística demonstraram que o gestor teve influência na sobrevivência das empresas em três variáveis (Gestão Própria, Empresa familiar e Escolaridade), entretanto outros fatores dividiram esta responsabilidade com os gestores: a prática da relação com o fornecedor; e o ambiente (PIBMEDIA e FROTAMEDIA).

A primeira variável em destaque foi a variável GESTÃO (Gestão Própria) com efeito negativo em relação à mortalidade. O sinal negativo no resultado do modelo logístico representou menor influência sobre a "morte" da empresa, ou seja, as organizações que eram geridas pelo proprietário ou um dos sócios tiveram menor incidência de extinção. Portanto, o antigo ditado popular "O olho do dono é que engorda o gado" se aplica ao varejo de pneus na Bahia, pois as empresas geridas pelo proprietário ou um dos sócios tiveram menos chances de morte. Uma preocupação que surgiu nos resultados da regressão logística nesta pesquisa foi o fato de que os gestores que têm relação familiar com os proprietários das empresas, mas não são sócios, têm uma tendência a falir suas respectivas empresas. Enquanto as empresas geridas pelo proprietário ou um dos sócios tiveram mais perspectiva de vida. Portanto, a importância do praticante central das estratégias (o gestor) ter habilidades, formação e capacidades necessárias para o bom desempenho organizacional se sobrepõe a quaisquer rótulos de confiança e afeto de um familiar, em relação à sobrevivência empresarial.

A importância do gestor na sobrevivência das empresas também foi confirmada com a significância da variável escolaridade do gestor. As empresas que tinham o gestor com

Organizadores:

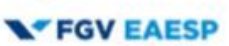

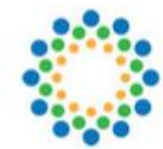

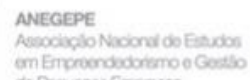
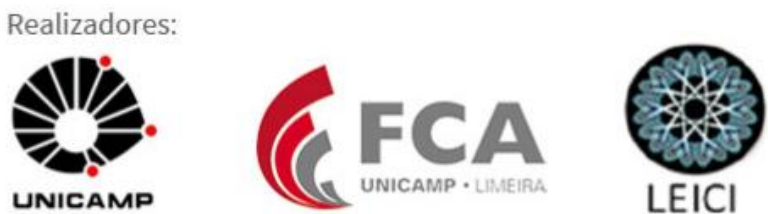
formação superior tiveram menor o risco de morte. Portanto, diferente de Mizumoto et al (2010) e semelhante aos estudos de Ferreira et al (2012), os resultados encontrados nesta pesquisa com os varejistas de pneus da Bahia evidenciam que a escolaridade com formação superior dos gestores teve influência negativa em relação à mortalidade. Quando associamos este resultado ao fato que as variáveis relacionadas às experiências anteriores do gestor, tanto no ramo como com liderança, não tiveram significância, podemos inferir que, diante de um mercado cada vez mais competitivo e instável, mais importante do que a experiência são os novos conhecimentos adquiridos pelos gestores com mais escolaridade.

Quanto à prática estratégica do relacionamento com fornecedores teve relevância ao ser verificada à significância da variável Monomarca. Constatou-se que as empresas multimarcas tiveram maior perspectiva de vida do que as monomarcas. Este resultado contraria um pensamento comum no mercado varejista pneumático de que ser monomarca, ou seja, ter maior relacionamento com um grande fornecedor ao se comercializar prioritariamente uma marca de pneu, fortaleceria a empresa varejista. Até o início desta pesquisa não houve trabalhos anteriores específicos para analisar as vantagens de ser monomarca ou multimarcas e qual o reflexo desta escolha estratégica na sobrevivência do varejista de pneus. As decisões tomadas sobre o relacionamento com fornecedores, de comercializar uma ou diversas marcas de pneus, eram tomadas pela tradição ou por uma prática predominante no mercado. Diante desta realidade, além do ineditismo desta pesquisa, segundo os resultados encontrados com a amostra total, as empresas multimarcas, ou seja, as que optaram pela prática estratégica de se relacionar com diversos fornecedores, tiveram menor incidência de extinção e maior tempo de vida.

Um dos objetivos específicos era identificar se o gênero do gestor teve influência na sobrevivência das empresas. Este fator foi confirmado na descrição da amostra onde se verificou que todas as empresas extintas eram geridas por homens e todas as 21 empresas geridas por mulheres estão entre as sobreviventes no período. Este sucesso das mulheres gestoras, pois embora tenham sido minoria, todas as empresas administradas por mulheres estão entre as sobreviventes. Isto merece ser aprofundado em novos estudos principalmente por ser o universo automotivo predominantemente masculino.

Espera-se também que o caráter pioneiro desta pesquisa possa suscitar novos estudos nesta mesma comunidade com períodos diferentes, ou ampliando para outros estados do Brasil, ou ainda estendendo para outros segmentos do setor automotivo que, embora tão presente no cotidiano da sociedade, ainda é muito carente de pesquisas.

Dentre as limitações deste estudo, podemos destacar a dificuldade ao acesso de informações das empresas varejistas de pneus, tanto vivas como mortas. Os gestores de empresas ativas evitam responder pesquisas por terem o tempo prioritariamente focado nos seus negócios ou por desconfiança do uso indevido das suas informações ou, ainda, por desconfianças de abrir emails infectados por vírus, já que os formulários de pesquisa foram enviados por email com um link. Quanto às empresas extintas, a dificuldade foi a localização e contato com os antigos gestores. Outra limitação foi a falta de organizações e associações de empresas deste setor atuantes no estado da Bahia. 


\section{Referências}

ASSOCIAÇÃO NACIONAL DA INDÚSTRIA DE PNEUMÁTICOS (ANIP). Anip em números. Disponível em: <http://www.anip.com.br/> acessado em 14/06/2015.

ASSOCIAÇÃO NACIONAL DOS FABRICANTES DE VEÍCULOS AUTOMOTORES (ANFAVEA). Anuário da Indústria Automobilística Brasileira. Disponível em: <http://www.anfavea.com.br/anuario.html.> Acessado em 14/06/2015.

BAUM, Joel.A.C. Ecologia organizacional. In: Clegg, S. R.; Hardy, C.; Walter R.N. (Org).Handbook de estudos organizacionais: modelos de análise e novas questões em estudos organizacionais. 1. Ed. 3. Reimpressão. São Paulo: Atlas, 2006.p.135-193.

CALDAS, M.; CUNHA, M. P. Ecologistas e economistas organizacionais: o paradigma funcionalista em expansão no final do século XX. Revista de Administração de Empresas, v. 45, n. 3, p. 65-69, 2005.

CUNHA, Miguel Pina. Ecologia Organizacional: implicações para a gestão e Algumas pistas para a superação de seu caráter anti-managemente. RAE, v. 39, n. 4, out/dez 1999, p. 21-28.

DEPARTAMENTO ESTADUAL DE TRÂNSITO DA BAHIA. Coordenação de Planejamento, Gestão e Estatística. Frota de veículos e Habilitados em Salvador. 2015.

DOMINGUES, L. M.; MURITIBA, P. M.; MURITIBA, S. N. Boa Governança Corporativa em Micro e Pequenas Empresas Leva à Internacionalização? . Contextus - Revista Contemporânea de Economia e Gestão, v. 14, n. 3, p. 53-78, 2016.

HANNAN, Michael T.; FREEMAN, Jonh. Ecologia das populações organizacionais. RAE, v. 45, n. 3, jul/set 2005.

FÁVERO, L. P.; BELFIORE, Patrícia; SILVA, F. Lopes; CHAN, Betty. Análise de dados: modelagem multivariada para tomada de decisões.Rio de janeiro: Elsevier, 2009.

FÁVERO, Luiz Paulo. Análise de dados. 1.ed. Rio de Janeiro: Elsevier, 2015.

FERREIRA, Luis Fernando Filardi et al. Análise quantitativa sobre a mortalidade precoce de micro e pequenas empresas da cidade de São Paulo.Gestão e Produção, v. 19, n. 4, p. 811823, 2012.

JARZABKOWSKI, Paula; WILSON, David C. Pensando e agindo estrategicamente: novos desafios para a análise estratégica. Revista de administração de empresas, v. 44, n. 4, p. 11-20, 2004.

JARZABKOWSKI, Paula; BALOGUN, Julia; SEIDL, David. Strategizing: The challenges of a practice perspective. Human relations, v. 60, n. 1, p. 5-27, 2007.

JARZABKOWSKI, Paula et al. On the risk of studying practices in isolation: Linking what, who, and how in strategy research. Strategic Organization, p. 1476127015604125, 2015.

MACIEL, Cristiano De Oliveira; AUGUSTO, Paulo Otávio Mussi. A practice turn e o movimento social da estratégia como prática: está completa essa virada?. Revista de Administração Mackenzie, v. 14, n. 2, p. 155, 2013.

MACIEL, Cristiano Oliveira; AUGUSTO, Paulo Otávio Mussi. Praticantes da estratégia e as bases praxeológicas da indústria do management. Revista de Administração de Empresas, v. 55, n. 6, p. 660-672, 2015.

MIZUMOTO, F. M.; ARTES, R.; LAZZARINI, S. G.; HASHIMOTO, M.; BEDÊ, M. A. A sobrevivência de empresas nascentes no Estado de São Paulo: um estudo sobre capital 
humano, capital social e práticas gerenciais. $R$. Adm., São Paulo, v. 45, n. 4, p. 343-355, out./nov./dez. 2010.

NELSON, Reed Elliot; PIMENTEL, Thiago Duarte. Perspectiva Weberiana para a Governança de Empresas Familiares: notas a partir de um estudo com empresas longevas. Organizações \& Sociedade, v. 22, n. 75, 2015.

ROCHA, Cláudio Figueiredo. Mortalidade empresarial: um estudo sobre a relação entre idade, tamanho e ambiente na indústria de alimentos da Bahia. 2015. 73f. Dissertação (Mestrado em Administração Estratégica)-Programa de Pós-Graduação em Administração da Universidade Salvador - UNIFACS, Salvador, 2015.

SANTOS, Ana Clarissa. Evolução das organizações por meio das abordagens institucionais, ecologia das organizações e equilíbrio pontuado. Revista de Administração da UFSM, v. 6, n. 1, p. 91-102, 2013.

SANTOS, Jason L. A.. Ecologia Populacional das Organizações Varejistas de Pneus em Salvador. In: XVIII SEMEAD, 2015, São Paulo. Anais do XVIII SEMEAD Seminários em Administração da USP. São Paulo: FEA / USP, 2015.

SANTOS, Jason L. A.. Evolução das Condições de Competitividade no Setor do Varejo de Pneus em Salvador. In: CLAV 2015, São Paulo. Anais do 8. Congresso Latino-Americano de Varejo. São Paulo: FGV-EASP/CEV, 2015. v. 1. p. 903-918.

SILVA ANDRADE, Luís Fernando et al. Desvelando o Campo da Estratégia Como Prática e suas Relações. Revista Ibero-Americana de Estratégia (RIAE), v. 15, n. 1, 2016.

SOUZA, Maria Carolina de Azevedo Ferreira de, et al. Pequenas empresas industriais de longa permanência no mercado: uma análise a partir da literatura e de evidências empíricas. Gestão \& Produção, 2014.

SUPERINTENDÊNCIA DE ESTUDOS ECONÔMICOS E SOCIAIS DA BAHIA (SEI). Índice de Performance Econômica e Social da Bahia. Salvador, 2016.

VAARA, E.; WHITTINGTON, R. Strategy-as-practice: taking social practices seriously. The Academy of Management Annals, v. 6, n. 1, p. 285-336, 2012.

VALADÃO, José de Arimatéia Dias; SILVA, Soraya Sales Dos Santos E. Justaposições da estratégia como prática e processo de estratégia: antes da visão pós-processual da estratégia. Revista de Administração Mackenzie, v. 13, n. 2, p. 171, 2012.

VILlAR, E. G.; WALGER, C. S.; ABIB, G.; ROGLIO, K. D. Processo Decisório como Prática Social: As Contribuições da Estratégia como Prática para os Estudos de Processo Decisório. Anais do Encontro Nacional da Associação dos Programas de Pós-Graduação e Pesquisa em Administração, 2015.

WHITTINGTON, Richard. Estratégia após o modernismo: recuperando a prática. Revista de Administração de Empresas, v. 44, n. 4, p. 44-53, 2004.

WHITTINGTON, Richard. Strategy practice and strategy process: family differences and the sociological eye. Organization studies, v. 28, n. 10, p. 1575-1586, 2007. 